\title{
A Moorean defense of the omnivore?*
}

\author{
Tristram McPherson \\ Virginia Tech \\ dr.tristram@gmail.com \\ Ms. for submission to Stirring the Pot \\ April 3, 2014 \\ Please do not cite or circulate without permission, comments welcome
}

\section{Introduction}

Most of us are unreflective omnivores. We consume meat, and other products made from or by non-human animals, without pausing to wonder whether doing so might be wrong. The permissibility of this behavior can seem like a bit of ethical common sense. However, common sense can be challenged, and the acceptability of eating meat has been challenged repeatedly. Sometimes the challenge takes the form of grisly images of cruelty to animals, or blunt slogans like "Meat is Murder". However, the challenge also takes another, more reasoned, form. Many philosophers have argued forcefully that eating meat is wrong. A conscientious omnivore might seek to wade through this sea of arguments, and try to find flaws in each one, but that would be a Herculean task. This paper examines another way of trying to answer these ethical challenges to the omnivore's lifestyle. This is to adapt a form of argument originally developed by G. E. Moore to argue against the skeptic (who claims that we know vastly less than we ordinarily think we do) and other revisionary philosophical views. Because Moore used his argument to defend commonsensical views about knowledge and reality against revisionary challenges, the omnivore might hope that Moore's style of argument would be similarly effective against the revisionism of the ethical vegetarian.

This paper examines the attempt to adapt Moore's argument on behalf of the omnivore. I first introduce and explain Moore's argument against the skeptic. I then explain how that argument can be adapted to address two influential philosophical arguments against the omnivore, due to Tom Regan and James Rachels. The adapted Moorean arguments appear strikingly similar to the original. However, I go on to argue that we should not simply assume that all Moorean arguments are created equal. Instead, I 
propose a set of principled criteria that can be used to test Moorean arguments on a caseby-case basis. Those criteria give the Moorean reason for optimism against the skeptic, but suggest that the Moorean's case is much weaker against the ethical vegetarian. I conclude that the Moorean omnivore's argument has potentially uncomfortable implications for all sides in debates about ethical vegetarianism, and illuminates important and neglected questions about the force of philosophical arguments in applied ethics.

\section{A brief introduction to Moorean arguments}

In order to explain the Moorean strategy, it will be useful to have a skeptical argument as a foil. Arguments for skepticism are many and varied, but I will focus on a single simple skeptical argument:

1. If my evidence would appear identical given a certain hypothesis, then I do not know that hypothesis to be false

2. My evidence would appear identical if $I$ were a brain in a vat whose (overwhelmingly false) beliefs about the world were responses to the ways that the scientists who run the vat stimulated my brain, rather than to ordinary sensory contact with the world

3. If I do not know that I am not a brain in a vat, then (among many other things) I do not know that I have hands

C. I do not know that I have hands

This argument talks about evidence: think of evidence as the set of reasons someone has for thinking that a claim is true. This argument is represented as a series of numbered premises. That helps to distinguish each of the key claims that the skeptic appeals to in supporting her conclusion. All of the premises of this argument are needed to support the conclusion: The first two premises entail that you do not know that you are not a brain in a vat. The third premise claims that if this is true, then you do not know many seemingly obvious propositions about the world, such as the proposition that you have hands.

What is the anti-skeptic to do, when confronted with this argument? The argument can be seen as implicitly posing a challenge to the anti-skeptic: "So you don't like my conclusion? Well, if each of these three claims are true, that conclusion must be true. So tell me what you think is wrong with one of these claims!" Understood as posing a 
challenge in this way, the argument appears powerful, because each of its premises seems very credible. I will briefly explain why each of these premises is hard to resist.

The first premise can be motivated by example. Suppose that you have friends with identical twin toddlers Allie and Sally. One day you visit them, and your friends have dressed their daughters identically. While this is adorable, you find that it is impossible for you to distinguish the twins when they are dressed this way. Suppose that one of them runs by, and you form the belief that it was Allie. Because you cannot tell the twins apart, your visual evidence would have appeared identical if it had been Sally who ran by. This seems to show that you do not in fact know that it was Allie and not Sally who ran by. The first premise of the skeptic's argument seems to be an excellent explanation of why this is so.

Next consider the second premise. It seems imaginable that sophisticated scientists could keep someone's brain alive in a vat, and immerse that person in a virtual reality by directly stimulating relevant parts of the brain. If the scientists were sophisticated enough, it further seems possible that the evidence the person received as a result of such stimulation would be indistinguishable by that person from an ordinary sensory experience. After all, the brain is connected to the sense organs and the rest of the body by a complex series of electrochemical connections, so it seems that it should in principle be possible to mimic those connections. This means that the hypothesis described by the second premise appears possible, making the second premise hard to deny.

The third premise also appears very plausible. In order to know that you have hands, it must be true that you do have hands. But brains in vats don't have hands. So (by the same reasoning that supported the first premise) you seemingly cannot know that you have hands without knowing that you are not a brain in a vat.

To be clear, philosophers have found important ways to challenge each of these premises, but doing so is clearly a difficult task. The Moorean responds differently, rejecting the skeptic's conclusion without explaining what is wrong with any of the skeptic's premises. By doing so, the Moorean refuses to take up the skeptic's challenge, mentioned above. Because of this, some have taken the Moorean to be objectionably dogmatic. The Moorean, on this reading, fails to "follow the argument where it leads".

A much more charitable understanding of the Moorean is possible, as I will now show. Imagine combining the skeptic's three premises into one big claim: call this the 
conjunction of the skeptic's claims. It is agreed on all sides that the skeptic's conjunction is inconsistent with I know I have hands. Suppose that you notice that you accept the conjunction, that you also accept I know I have hands, and that this means that you accept inconsistent claims. One way to address this inconsistency is to recheck the apparent evidence you have for each of the inconsistent claims. For example, if such rechecking convinced you that you have no reason to accept the first premise of the skeptic's argument, this would allow you to resolve the inconsistency by rejecting that premise. But suppose that no such resolution is available. Then you should presumably attempt to weigh the evidence you have for each of the inconsistent claims against the evidence you have for the other.

The important thing to notice, from the Moorean's point of view, is that you can have much stronger evidence for a claim (such as I know I have hands) than for a conflicting claim (such as the skeptic's conjunction) without knowing why the conflicting claim is false. Consider an analogy: suppose that after dinner at the restaurant, your four friends each independently calculate the split bill, while you savor your dessert. Three of your friends conclude that each person owes exactly $\$ 18.62$, while the fourth concludes that each owes $\$ 16.27$. Other things being equal, this would give you good reason to believe that your three friends got it right, because there is little chance that they all miscalculated in precisely the same way. But notice that this reasoning does not (and need not) shed light on why your fourth friend's conflicting answer is wrong. If the analogy holds, the skeptic's challenge may be illegitimate: it may be sensible to reject the skeptical argument without explaining where it goes wrong.

The Moorean embraces this idea, claiming that the evidence for I know I have hands is much stronger than the evidence for the skeptic's conjunction, and that it is thus reasonable to continue to believe one has hands, even in face of the conflict with that conjunction. ${ }^{1}$ It is worth emphasizing that for the Moorean to be correct about this, the evidence for I know I have hands needs to be significantly stronger than the evidence for the conjunction, and not merely slightly stronger. This is because if your evidence for each of two conflicting claims is close to equally strong, you should suspend judgment about both of them. To see this, suppose that you have been looking at apartments to rent with your friends, Chuck and Diane. You try to remember the color of the kitchen in the second 
apartment, but draw a blank. When you ask your friends, Chuck is confident that the kitchen was beige, and Diane that it was yellow. Suppose that you have reason to trust Diane a bit more on these things; she is usually slightly more attentive to visual details than Chuck. So, if you needed to bet on the color of the kitchen, it would make sense to bet it was yellow. Still, given your friends' conflicting testimony, you should not believe either that the kitchen was beige or that it was yellow, until you get further evidence: you should suspend judgment about both claims.

\section{The Moorean case for the omnivore}

With the Moorean's basic reasoning in hand, I will now explain how this reasoning can be adapted by the omnivore. The case against the skeptic used the skeptic's argument as a foil, so I begin by introducing foils here as well. As with skepticism, philosophical arguments for vegetarianism are many and varied. One important way that they vary is in the scope of the ethical principles that the vegetarian defends and applies. Some philosophical vegetarians develop and then apply comprehensive ethical theories. Others appeal to local ethical principles that do not purport to explain the rightness or wrongness of every action. Consider an influential instance of each approach.

Tom Regan's case for animal rights (2004) develops and applies a comprehensive ethical theory. Regan argues that individuals possess various moral rights, which directly reflect the inherent moral worth of those individuals. By seeking to ground rights directly in moral worth, Regan raises a pressing question. On any plausible view of rights, some things (e.g. you and I) possess rights (and hence inherent moral worth), while others (e.g. a shard of broken plastic) do not. What explains the difference? Regan argues that many initially plausible answers to this question are indefensible. For example, consider the idea that inherent moral worth requires capacities for ethical agency or sophisticated rational thought. This would entail that non-human animals lack rights. However, it would also entail that many humans - for example young children and severely mentally handicapped adults - lack rights. And this is implausible. Or consider the idea that having moral worth requires being a member of the species homo sapiens. This avoids the problems facing the rational capacity idea, but it looks like an attempt to explain a fundamental ethical property by appeal to something ethically irrelevant. To see this, imagine that we discovered an alien 
species with capacities to think, feel, love, and act that are very like our own. Mere difference in their genetic code surely cannot deprive them of rights. According to Regan, the only defensible alternative is that a sufficient criterion for having intrinsic worth is being the experiencing subject of a life $(2004, \S 7.5)$. Since many of the animals that humans eat and otherwise use are experiencing subjects of lives, Regan concludes that these animals have moral rights that are just as strong as ours.

Arguments for vegetarianism need not appeal to ambitious claims about the structure of morality, as Regan's does. James Rachels' (1977) argument begins with the simple and plausible thought that it is wrong to cause suffering and death to sentient beings unless one has a strong reason to do so. Contemporary ways of raising animals for food cause an extraordinary amount of suffering and death to sentient beings, and Rachels argues that the various reasons that humans typically have for raising animals for meat do not constitute a strong enough reason to outweigh the presumptive wrongness of this practice. Contemporary practices of raising animals for meat are thus wrong. It might be noted that the ordinary omnivore does not cause animals to suffer or die: she buys her meat already dead. In order to address this point, Rachels (like Regan) argues for the further thesis that it is wrong to purchase and consume meat, given how ethically objectionable its production is.

These arguments do not merely imply that we should stop eating meat. The suffering that Rachels objects to is a feature of most contemporary animal farming, so his argument would generalize to rule out eating eggs or dairy products. Further, the amount of suffering inflicted by contemporary animal farming boggles the mind: many billions of animals suffer and die every year in the system that produces our meat farming. Following James Rachels in admitting the ethical significance of animal suffering thus appears to suggest that our contemporary relationship to farm animals is not merely wrongful; it is an ethical catastrophe. ${ }^{2}$ Regan's view arguably has even more radical implications: it makes the omnivore's dinner and the cannibal's appear strikingly ethically similar. These arguments raise further important questions about whether the ethical vegetarian should even tolerate the company of omnivores (for a vivid depiction of someone struggling with the radical implications of related ideas, see J. M. Coetzee 2001, especially 19-20 and 689). In light of these considerations, it is fair to describe these leading philosophical 
arguments for vegetarianism as radically revisionary of common ways of thinking about the ethics of our relationship to animals.

This description encourages the thought that the omnivore can cast herself in Moorean clothes, as the defender of common sense against philosophical attack. Theses such as it is not wrong to drink a glass of milk or it is not wrong to eat some chicken appear to be bits of ethical common sense: they are widely held, and typically taken for granted as obvious. (Of course, if you are reading this volume, you may not take these claims for granted. And this may lead you to doubt that they really are commonsensical. But the same would seemingly be true of I know that I have hands, if you were earnestly reading a volume on skepticism.) The thought that the omnivore is warranted in adopting the Moorean guise is further encouraged by Kit Fine's gloss on the core Moorean idea:

[I]n this age of post-Moorean modesty, many of us are inclined to doubt that philosophy is in possession of arguments that might genuinely serve to undermine what we ordinarily believe. $(2001,2)$

Fine's suggestion here amounts to the idea that commonsense beliefs may be systematically more reasonable than the conclusions of any philosophical arguments inconsistent with them.

The structure of the Moorean reply to our two philosophical arguments for vegetarianism is the same as it was against the skeptic. First, join together all of the claims required by the vegetarian to make her argument. Then note that together, these claims are inconsistent with the truth of a commonsensical claim like it is not wrong to drink a glass of milk. Then claim that it is most reasonable, in the face of this conflict, to retain the commonsensical claim.

Fine's suggestion provides reason for optimism about this strategy. After all, Regan's and Rachels' arguments are both uncontroversially philosophical. Thus, Regan's argument requires the premises that being an experiencing subject suffices for possessing rights and that it is wrong to consume products that were produced in ways that violate rights, both of which are substantial theoretical claims defended by philosophical argument. Similarly, Rachels' argument requires the premises that it is wrong to cause suffering (even to animals) without very good reason, that there are insufficient reasons to justify causing the suffering involved in the production of meat and dairy, and that it is wrong to consume products that were produced wrongfully, all of which are significant claims defended by philosophical argument. 
These examples illustrate a general recipe that the Moorean omnivore can use against arguments for vegetarianism. Given the broadly commonsensical status of omnivorism, it is plausible that any argument against the omnivore will need to appeal to some philosophically substantive ethical claims. These might be ambitious theoretical principles (like Regan's rights view), or more local ethical principles (like Rachels'). Or they might be at some intermediate level of generality. But in any such case, a relevant inconsistent package can then be constructed. And then Moorean modesty about the force of philosophy against common sense will suggest that the omnivore's thesis should be retained in such conflicts.

\section{Evaluating the Moorean omnivore}

So far, I have sought to explain the Moorean omnivore's strategy, and present it in a sympathetic light. I now turn to the task of evaluating that strategy. In order to do so, I will propose and apply a general set of criteria for assessing claims about the relative strength of bodies of evidence. I begin with some critical comments about Kit Fine's suggestion, which motivate the search for such general criteria.

Fine suggests that philosophy lacks arguments that could give us reason to abandon what we ordinarily believe. We should ask: is this suggestion (if true) explained by the special strength of common sense, or by the special weakness of philosophy? The latter is undoubtedly the more plausible version of the view. After all, common sense should yield in the face of well-confirmed scientific hypothesis. Consider for example the foolishness of trying to deploy common sense against the hypothesis (entailed by Einstein's theory of general relativity) that space itself is curved.

Fine's suggestion is thus best understood as espousing modesty about what philosophical arguments can lead us to reasonably believe. This modesty may seem both reasonable and appealing, given the long history of philosophers' succumbing to intellectual overreach. The appeal of this attitude collapses under scrutiny, however, when we consider its application to ethics. Adopting Finean modesty here would threaten to transform the field into an exercise in apologetics, limited to generating explanatory frameworks to underlie, organize, and extend the views that we all already accept. 
Of course, the fact that modesty about the force of philosophical argument is unappealing does not show that it is unreasonable. But here again, reflection on ethics suggests reasons for doubt. Consider an historical context in which the ethical acceptability of radical racial and gender inequality was generally treated as commonsensical. Imagine someone bringing careful exposition of our best arguments against such inequality to ordinary people in this context. Set aside how persuasive such exposition would likely have been. Instead ask: could our speaker's audience be reasonable in holding unreformed racist or sexist ethical beliefs after understanding the speaker's arguments? I strongly suspect not. More modestly, Fine's suggestion is not obviously plausible when we consider such cases.

This suggests that we should not take the reasonableness of all Moorean arguments for granted. We should instead seek a principled method for evaluating them. Recall that, rather than challenging one of the premises of a revisionary argument, the Moorean claims that the evidence supporting her commonsensical thesis is much better than the evidence supporting the revisionist's premises. Because of this, evaluating a Moorean argument essentially involves assessing claims about the relative strength of the evidence that supports conflicting claims. Performing this evaluation therefore requires us to find secondorder evidence: evidence concerning how strong our evidence for a claim is.

One might worry that there will be nothing principled to say here: after all, one might expect it to be at least as hard to assess second-order evidence as it is to assess the first-order evidence directly. The approach that I propose is tailored to meet this concern. The basic idea is to identify general features, the presence or absence of which would, other things being equal, reasonably lead us to raise or lower our estimation of how wellsupported belief in a claim is. I call such features generic indicators of strength of evidence. ${ }^{3}$ Because they are generic, the indicators I propose are well-suited to provide principled (although defeasible) support for one view over another, in a controversy over the strength of evidence for a claim.

I cannot canvass every possible such indicator here. I focus on five indicators that I take to be crucial for evaluating Moorean arguments. These indicators are:

1. Relative confidence in the Moorean and revisionary theses

2. Prevalence of philosophically naïve proponents of the conflicting theses

3. Extent and nature of the change to our beliefs required by the revision

4. Relative fit of the conflicting theses with our epistemic paradigms 
5. Relative vulnerability of the conflicting theses to debunking explanations

A Moorean thesis is just the central claim that some Moorean hopes to defend. In our cases, the Moorean thesis is it is not wrong to drink a glass of milk. A revisionary thesis is the claim targeted by a Moorean argument. In our cases it is: it is wrong to consume animal products. I now briefly explain the significance of each of the five indicators mentioned. ${ }^{4}$

First, consider the idea that one's degree of confidence in a belief is second-order evidence of how strong one's evidence for that belief is. This idea is required by ordinary trust in oneself as a believer. To see this, imagine what one's inner life would be like, if one took one's relative confidence to be no guide to what to believe. I tenuously believe that I left my keys on the desk, but (looking at the desk) I find myself very confident that I do not see them, that my eyes are functioning normally, and that my keys have not become invisible. It would be absurd to discount this confidence when considering what to believe about the location of my keys. Like all of the indicators, the evidence provided by confidence can be undercut. I might learn from experience, for example, that I have systematically inflated confidence in some of my beliefs about my own ability or performance. This would give me reason to discount that confidence.

The second indicator is non-philosophical consensus. One case for the significance of consensus simply generalizes trust in oneself. The idea is that, if one trusts one's own thinking, and one has no evidence that others are worse thinkers on a topic (or deceitful), one should extend one's trust to those others. This appears especially plausible where others speak with one voice. This indicator's focus on non-philosophical consensus is more controversial: if we took philosophers to be experts on a question, and non-philosophers to be amateurs, it would seemingly make more sense to consider the weight of philosophical opinion. (Compare the way that it will often be reasonable to follow scientific opinion in the face of non-scientific consensus.) The Moorean project is most promising if we assume that philosophers are not experts on the relevant topic. For if they were, the nonphilosophical consensus that we know we have hands, for example, would have little significance against the skeptic. ${ }^{5}$ This is a complicated issue, but I will grant the Moorean this assumption for the sake of argument.

The third indicator is the extent and nature of the change to our beliefs required by the revisionary thesis. The basic idea here is straightforward: we tend to have evidence for 
what we believe. As a revisionary thesis challenges more (and more topically diverse) of our beliefs, we thus have reason to believe that it conflicts with more and more of our evidence.

The fourth indicator concerns the relative fit of the Moorean and revisionary theses with our epistemic paradigms. These are our most central and clear guides to evidence and reasonable belief. These paradigms include sources of evidence (for example: sense experience), and ordinary inferential practices (for example, predicting that a past regularity will continue). They also include paradigms of epistemically successful enquiry (such as scientific enquiry). Together, these paradigms comprise much of our competence to evaluate epistemic claims. It is plausible that broad inconsistency with such paradigms is a powerful indicator that something has gone wrong with a piece of reasoning.

The final indicator is the relative vulnerability of the Moorean and revisionary theses to debunking explanations. An explanation debunks a claim if it offers a compelling explanation for the claim's apparent evidential status that gives us good reason to reject that status. A claim is more or less vulnerable to debunking explanation depending on how credible alleged debunking explanations of that claim are. If a claim is substantially vulnerable to debunking, this suggests that the evidence for it may not be nearly as strong as it otherwise appears to be.

With the five indicators briefly described and motivated, consider how they apply to the Moorean argument against the skeptic introduced above. Very briefly:

1. (confidence) I am enormously confident that I have hands. And the most radical skeptical doubts appear to have little persistent effect on this confidence. As David Hume noted, an evening of pleasant company and diversion is often enough to render skeptical speculation inert (2001 [1740] §1.4.7).

2. (philosophically naïve acceptance) Outside of the seminar room, radical skepticism is an extremely rare phenomenon, while belief in the possession of hands is ubiquitous, except in cases that are irrelevant to the skeptical challenge. (Some of us do lack hands and reasonably believe that.)

3. (extent of revision required) The skeptic's thesis requires wholesale abandonment of almost all of one's beliefs about almost all topics. 
4. (fit with epistemic paradigms) The skeptic's thesis is inconsistent with many of our epistemic paradigms, since it would require us to distrust or abandon them.

5. (vulnerability to debunking) Independent of the skeptical challenge at issue, the belief that I have hands does not appear particularly vulnerable to debunking explanation (although the skeptic's revisionary argument is not particularly vulnerable in this respect either).

Together, these indicators constitute a significant case that the Moorean thesis is much better supported by our evidence than the skeptic's revisionary alternative.

I take the generic indicators account just sketched to provide the most promising principled defense of the strength of traditional Moorean arguments against the skeptic. The account focuses on the crucial question of how to assess competing claims about the relative strength of competing evidence. The account appeals to informative and seemingly relevant considerations. And the Moorean case shines relative to these considerations. This account also protects the Moorean from implausible overgeneralization: for example, it will not vindicate implausible Moorean attacks on well-supported but surprising scientific hypotheses. ${ }^{6}$

These virtues of the generic indicators account warrant treating that account as a criterion against which to assess more controversial Moorean arguments. I therefore now consider how the generic indicators apply to the Moorean omnivore's argument:

1. (confidence) Many of us are very confident that it is not wrong to drink a glass of milk, or eat a steak, even after encountering arguments for vegetarianism. However, the case here appears weaker than versus the skeptic. Most directly, it seems both rare and unreasonable to be as confident that it is okay to eat a steak, as one is that one has hands.

2. (philosophically naïve acceptance) The omnivore's key claims are widely accepted. However, we also see a small but significant group of non-philosophical vegetarians, living their commitment to the revisionary thesis. By contrast, it is controversial whether anyone can fully embrace and live the skeptical perspective. In both of these cases, the indicator arguably does something to bolster the credibility of the Moorean argument, but the indicators are not as favorable as they were against the skeptic. The omnivore cannot make even this modest claim about the remaining indicators. 
3. (extent of revision required) Consistently adopting vegetarianism is clearly a significant change in one's ethical outlook. However, compared with skepticism, it involves very limited adjustment to one's beliefs. For example, it will leave untouched almost all of one's non-ethical beliefs and many of one's ethical beliefs. In light of this, the Moorean omnivore fares poorly relative to the third indicator.

4. (fit with epistemic paradigms) Accepting the vegetarian's revisionary argument poses no significant threat to our epistemic paradigms. (The Moorean might insist that trust in common sense claims is itself an epistemic paradigm. If so, the vegetarian's argument threatens only this, as every revisionary argument must.) Indeed, the philosophical defender of vegetarianism might argue that, given the strength of arguments for her view, belief in vegetarianism might be an instance of being appropriately sensitive to those paradigms. So the Moorean omnivore fares poorly relative to the fourth indicator.

5. (vulnerability to debunking) The omnivore's Moorean thesis is substantially vulnerable to debunking explanation (as I now explain), and so the omnivore does poorly relative to the fifth indicator.

The most promising debunking argument against the Moorean omnivore's thesis (and related beliefs) is perhaps the suggestion that these are products of what I will call status quo rationalization. A belief is subject to status quo rationalization just in case that belief is required to vindicate the goals and behaviors of the believer, and of others that the believer identifies as members of her ethical community. Consider as an example a member of a slave-owning family in the antebellum South, for whom owning and using slaves is a deeply embedded part of everyday life, and the life of those he is closest to. It is easy to predict that other things being equal, such a person will tend not to believe that slavery is a moral monstrosity. This is because taking oneself and those one identifies most closely with to be doing something seriously wrong makes for a particularly uncomfortable form of cognitive dissonance: very few people can comfortably identify themselves and their loved ones as morally bad (for dramatization of this point, see Coetzee 2001, 68-9). The more deeply embedded a behavior is in one's life - the more convenient or beneficial or pleasant; the more unquestioned by one's peers and loved ones - the more likely it is that the cognitive dissonance will be resolved by one's values changing in order to 
rationalize one's behavior, and the behavior of those one identifies with. This is relevant because eating animal products is deeply embedded in most of our lives, in a way apt to produce such rationalization. A belief is especially vulnerable to such debunking explanation where we lack explanatorily satisfying arguments for its truth. A contrasting example: it would surely be very uncomfortable to abandon the belief that wanton killing is wrong; but we possess satisfying arguments that provide plausible explanations of why it is wrong, so this belief is not very vulnerable to this sort of debunking. ${ }^{7}$

To sum up: the Moorean omnivore can appeal to confidence and non-philosophical consensus as modest indicators of the strength of her argument. However, unlike the antiskeptic, she seemingly cannot appeal to the objectionably broad scope of the revision in question, or to the revision's inconsistency with our epistemic paradigms. Finally, the confidence and consensus that the Moorean omnivore appeals to is vulnerable to significant debunking explanation, in a way that the Moorean anti-skeptic appears not to be. Recall that Moorean arguments have a very high standard for success: they need to make it reasonable to retain belief in the face of a competing argument, rather than either accepting the competing argument, or suspending judgment. The five indicators canvassed strongly suggest that it is not plausible that the omnivore meets this standard. In light of this, the Moorean strategy fails to show that it is reasonable to be an omnivore in the face of philosophical arguments for vegetarianism.

\section{Conclusions and Implications}

This paper has explored a Moorean strategy for defending the omnivore's lifestyle against the challenged posed by philosophical arguments for ethical vegetarianism. This strategy initially appears attractive, because of the structural similarity of the Moorean omnivore's argument to the standard Moorean argument against the skeptic. However, I have argued that once we develop the tools to offer a principled assessment of possible Moorean arguments, we find that the omnivore's argument falls well short of the standard set by the case against the skeptic. I take my argument to be too brisk to be utterly decisive: it is best understood as providing a strong initial challenge to the reasonableness of being an omnivore on Moorean grounds. This challenge invites the omnivore to look elsewhere for a reasoned defense of her views: perhaps she can appeal in some other way to the 
apparently commonsensical status of omnivorism, or to piecemeal diagnoses of what goes wrong with the many ethical arguments for vegetarianism, or to a novel positive ethical argument for omnivorism.

In addition to this main challenge, my exploration of the Moorean omnivore's argument has interesting implications for the ambitions of philosophers, for Mooreans, and for the dialectic about vegetarianism. I close by briefly exploring these issues in turn.

First, my argument suggests that not all "common-sense" is created equal. In light of this, we should reject Kit Fine's proposal that common-sense is quite generally immune to philosophical revision. Further, the five indicators discussed here can be seen as providing a (provisional and sketchy) outline of the conditions under which philosophers can hope to reasonably challenge common sense. This is of crucial interest for philosophers, because the philosophical project looks very different depending on whether common sense is a legitimate target. Where common sense reigns supreme, philosophers are limited to helping us to better understand the philosophical alternatives that are compatible with common sense. Where common sense does not reign supreme philosophers may reasonably retain hopes of leading us closer to the truth - and away from the grip of rationalization and ideology - on matters of importance. This paper suggests that philosophers may retain such hopes concerning the ethical case for vegetarianism, and it is natural to think that the argument of this paper would generalize at least to other pressing issues in applied ethics.

Second, the failure of the Moorean omnivore's argument is crucially a matter of degree. If I am correct, her argument falls well short of the standard set by the paradigmatic Moorean arguments, and also well short of the standard required to secure knowledge. This does not mean that Moorean considerations have no probative force against the vegetarian, however. It is a difficult matter to assess exactly how much force they have. It might be argued on the basis of the first two indicators that the omnivore's Moorean considerations have just enough force to prevent arguments for vegetarianism from succeeding: that is, reflection on the Moorean argument might require us to suspend judgment concerning whether it is wrong to eat meat.

To be clear, I do not think that the Moorean argument succeeds even this much, but adequately defending this claim would require considerable (and difficult) argument 
that I have not provided. And this possible outcome of the debate should be of interest both to philosophers attracted to Moorean arguments, and to anyone interested in the ethical debate between the omnivore and the vegetarian.

The idea that a Moorean argument should lead us to suspend judgment is an important issue for Moorean philosophers to grapple with. It is also uncomfortable: Moore was in the business of trying to preserve knowledge, not destroy it. But once we notice that candidate Moorean arguments will fall on a spectrum, with Moore's own paradigms at the strong end, it seems inevitable that at least some such arguments will entail that we ought to suspend judgment.

The possibility that the philosophical arguments for vegetarianism and the Moorean case for the omnivore together deprive us of knowledge concerning what we may ethically eat is also practically important. It would suggest that the proponent of ethical vegetarianism and of omnivorism each believe more than is reasonable. This would be unnerving on all sides. It also raises the question of what we should do, if faced with this moral ignorance?

This is itself a vexed philosophical issue. ${ }^{8} \mathrm{I}$ am inclined to think that a precautionary principle may apply here: other things being equal, we have reason to avoid doing things that we have strong (even if not decisive) reasons to believe are wrong. Suppose this is right, and that, at that end of the day, while the philosophical vegetarian's case gives us reason to believe that it is wrong to eat meat, it falls short of securing knowledge. In this case the precautionary principle would suggest that the vegetarian's argument should govern our behavior, even if it does not command our beliefs. 


\footnotetext{
* I am indebted to an audience at Charles Sturt University for vigorous and helpful discussion of ideas that went into this paper. I am also indebted to Derek Baker, Mark Budolfson, David Faraci, Robert Fischer, and David Plunkett for illuminating comments. This paper draws in places on ideas previously developed in my (2012), (forthcoming), and especially (2009).

${ }^{1}$ Compare Moore $(1959,226)$, where he replies in roughly this way to an argument due to Bertrand Russell.

${ }^{2}$ Stuart Rachels (2011, especially §6) makes this case forcefully.

${ }^{3}$ For further discussion of the generic indicators idea, see my (2009) and (2012).

${ }^{4}$ I defend these indicators in more detail in my (2009).

${ }^{5}$ For one argument against the idea that philosophers are moral experts, which could be generalized to other topics of philosophical controversy, see McGrath $(2008, \S 5)$.

${ }^{6}$ See my $(2009,14-15)$ for discussion and defense of this claim.

${ }^{7}$ For more discussion of this debunking argument, see my (forthcoming).

${ }^{8}$ For a view on this question broadly sympathetic to my proposal below, see Moller (forthcoming); for a countervailing view, see Weatherson (forthcoming).
}

\section{Works Cited}

Coetzee, J. M. The Lives of Animals. Princeton: Princeton University Press, 2001.

Fine, Kit. "The Question of Realism.” Philosophers' Imprint 1.1 (June 2001). 1-30.

Hume, David. Treatise of Human Nature. Eds. D. F. Norton and M. J. Norton, Eds. Oxford: Clarendon, 2001.

McGrath, Sarah. "Moral Disagreement and Moral Expertise." Oxford Studies in Metaethics Vol. 3. Ed. Russ Shafer-Landau. Oxford: Oxford University Press, 2008. 87-107.

McPherson, Tristram. "A Case for Ethical Veganism: intuitive and methodological considerations. Forthcoming in Journal of Moral Philosophy.

--- "Moorean Arguments and Moral Revisionism." Journal of Ethics and Social Philosophy 3.1 (June 2009). 1-25.

---. "Unifying Moral Methodology.” Pacific Philosophical Quarterly 93 (2012). 523-549.

Moller, Dan. "Abortion and Moral Risk." Forthcoming in Philosophy

Moore, G. E. 1959. Philosophical Papers. London: George Allen \& Unwin.

Rachels, James. "The Moral Argument for Vegetarianism." Can Ethics Provide Answers? And Other Essays in Moral Philosophy. Lanham, MD: Rowman and Littlefield, 1997. 99107.

Rachels, Stuart. "Vegetarianism." Oxford Handbook of Animal Ethics. Eds. T. Beauchamp and R. G. Frey. Oxford: Oxford University Press, 2011. 877-905.

Regan, Tom. The Case for Animal Rights. ( $2^{\text {nd }}$ Ed.) Berkeley: University of California Press, 2004.

Weatherson, Brian. "Running Risks Morally.” Forthcoming in Philosophical Studies. 